\title{
Food Prices and the Politics of Hunger: Beneath Market and State
}

\author{
Haris Gazdar
}

\begin{abstract}
What accounts for the persistence of hunger and undernutrition in political and administrative systems which might be otherwise sensitive to the risk of food price volatility and market failure? If pre-empting food price volatility has a political constituency why is there not a similar constituency for preventing vulnerability to hunger? The policy response to globally-driven food price volatility in Pakistan was largely successful in achieving its proximate goals, and price spirals and market shortages in 2008 were aberrations from which lessons were drawn effectively. Research for the Life in a Time of Food Price Volatility project shows that the food economy of the poorest is relatively insulated from price fluctuations, and vulnerability to hunger is mostly driven by idiosyncratic shocks. The poorest often operate beneath the market, or at the lowest rung of a highly segmented market, and their expectations with respect to rights and entitlements to food correspond with their prevailing sources of informal social support.
\end{abstract}

\section{Introduction}

Pakistan does poorly with respect to most indicators of hunger and food security and the persistence of undernutrition in the country is at least partly attributed to inadequate food consumption.

According to statistics compiled by the Food and Agriculture Organization (FAO), while there had been a steady decline in the ratio since 2001, around a sixth of the population remained undernourished (Balagamwala and Gazdar 2014). In the nationally representative National Nutrition Survey of 2011 three-tenths of the respondents reported that household members had faced hunger at some time in the year, with a tenth saying that children had also gone hungry. Shortfalls in calorie consumption as well as periods of vulnerability to hunger, therefore, continued to affect 10-30 per cent of the population (Aga Khan University 2011).

The food crisis of 2007-09 revealed a political and administrative system which was not only responsive to price volatility but was effective, for the most part, in stabilising prices and preventing market failure. What accounts for the persistence of hunger and undernutrition in political and administrative systems which might otherwise be sensitive to the risk of price volatility and market failure with respect to essential food commodities? This article aims to answer this question using an understanding of the food economy of the poorest developed through a longitudinal qualitative study in rural and urban areas of Pakistan as part of the Life in a Time of Food Price Volatility project over the course of three years. The research examined the impact of food price volatility (FPV) on the poor in urban and rural areas through longitudinal case studies of 20 households, selected key informant interviews and focus group discussions (FGDs) with young and older women and men in the survey communities. The selection of study sites and households within these sites was premised on a focus on the poorest and socially marginalised. The rural fieldwork site consisted of villages in three administrative units of Taluka Johi of Dadu District, Sindh Province, which are situated about $15 \mathrm{~km}$ from the district headquarters. Agriculture is the main source of livelihood in this area, but lack of irrigation water means that there is only one crop (winter wheat) through the annual cycle. Some of the communities are dominated by large landlords who also wield political influence. For our urban site low-income neighbourhoods in Union Council 12 of Gulshane-Iqbal Town in Karachi were selected. This part of the city is a predominantly working class area with an ethnically mixed population, and with relatively good access to infrastructure and public services.

In this article, we argue that the food economy of the poorest is only partly dependent on markets and prices. As such, an implicit social contract that 


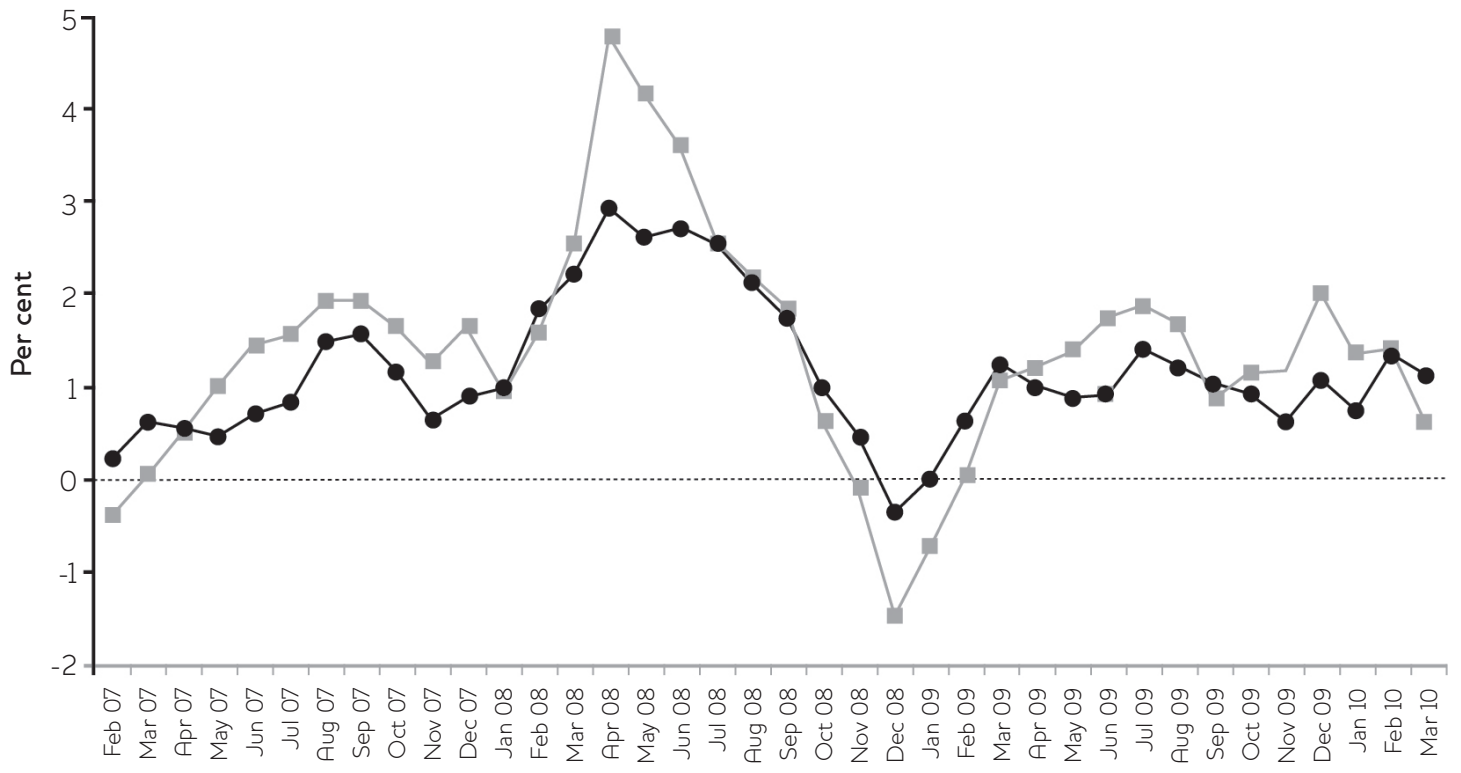

Source Gazdar and Mallah (2010) based on Economic Survey (various years). ${ }^{1}$

ensures stability in prices bypasses a large segment of the population which remains vulnerable to hunger beneath the market.

Thus, Section 2 describes the impact of the global food price crisis and its management in Pakistan and outlines the nature of the implicit social contract and its lapses. The food economy of the poorest is described in Section 3, which summarises qualitative findings from the FPV project on hunger, coping behaviour and informal social protection, and shows the relative insulation of the poorest from prices and markets. Section 4 examines observations from the FPV project on perceptions about accountability with respect to hunger, and how rights and entitlements to food and nutrition are understood by the poor. Conclusions are offered in Section 5.

\section{The food price crisis and its aftermath: global to national linkages and their management}

The global food price crisis of 2007-09 brought into relief the linkages between the global and national economies, and also the politics of the policy response. The three-year period from February 2007 to March 2010 during which global food and fuel prices rose saw particularly unstable prices in Pakistan (see Figure 1). During this time, the monthly inflation rate measured using the Consumer Price Index (CPI) peaked at 3 per cent.
In the calendar years 2007 and 2008 the monthly inflation rates of key food items such as wheat (the main staple) were even more volatile than the general price indices (see Figure 2). While the monthly inflation rate measured using the Sensitive Price Indicator (SPI) peaked at 5 per cent in April 2008, monthly wheat price inflation was at or above the 5 per cent mark for ten out of the 22 months covered. The closing months of 2007 saw the sharpest rises in wheat prices, coinciding with domestic shortages, high international prices, and suspicions of speculative collusive hoarding of wheat stocks by private parties. The presence of such distortions in the domestic market was acknowledged when the central bank banned bank borrowing for the purchase of wheat stocks (Iqbal 2007). It was suspected that speculative activity was financed by borrowing funds from commercial banks.

The government has historically purchased 10-20 per cent of the wheat harvest at a pre-announced procurement or support price to maintain public stocks of the staple grain. This is supposed to serve two purposes: first, a support price guarantee assures a predictable return to wheat growers, and second, the government releases grain from its stock to millers at this control price, thus providing a consumer subsidy by absorbing the cost of storage and transportation. Wheat is sown from November 


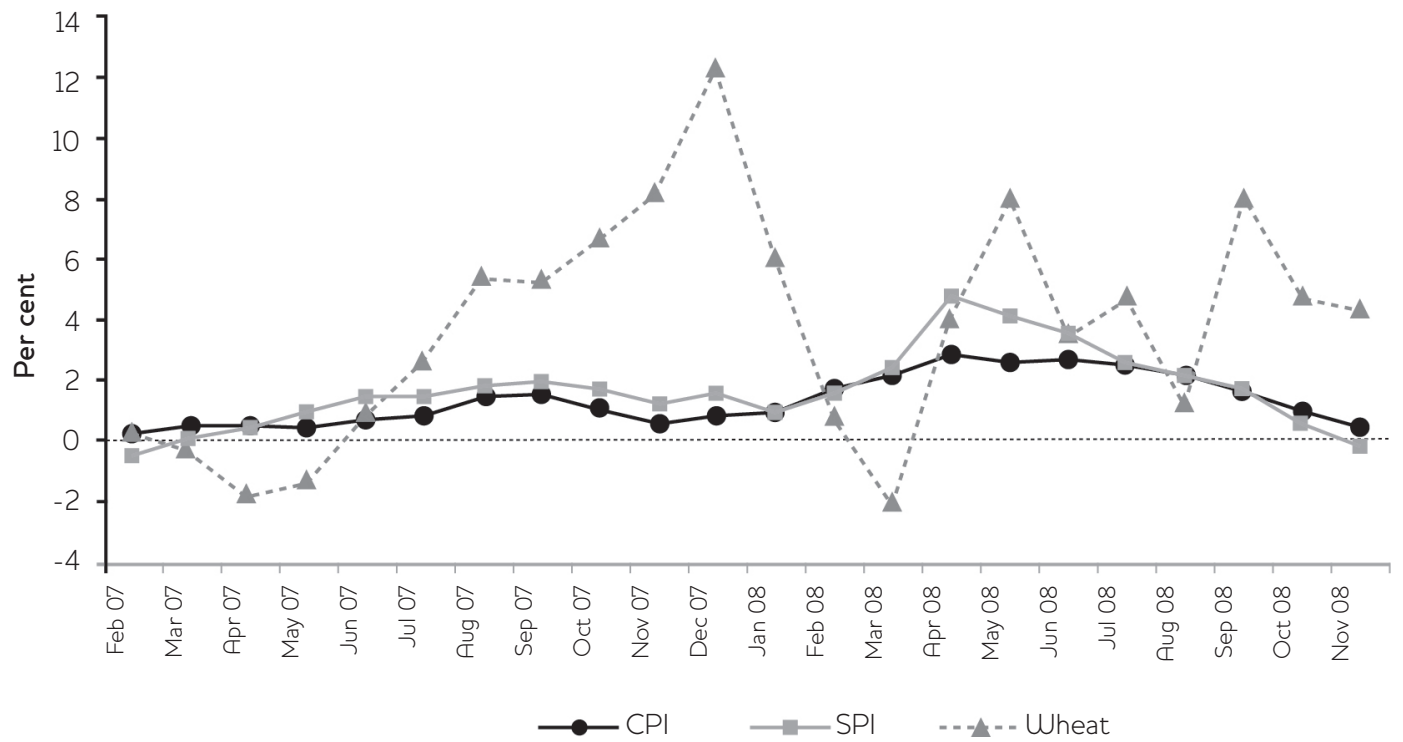

Source Gazdar and Mallah (2010) based on Federal Bureau of Statistics (various years), ' 'Monthly Review of Prices'3 and Economic Survey (various years). ${ }^{4}$

onwards and harvested during March and April. For the procurement price to act as an effective signal to growers, it is usually announced in October. As world prices began to rise in the middle of 2007, it was expected that the government would announce a significant hike in the procurement price for the 2008 harvest. In fact, no such announcement was made. Domestic prices followed the world market and by December 2007-January 2008 a crisis had erupted in the local markets as supplies dried up due to speculative hoarding by traders.

The food crisis in Pakistan coincided with a moment of political uncertainty and turmoil. General Pervez Musharraf's military regime which had been in power since 1999 faced popular protests from March 2007 onwards. The assassination of former Prime Minister Benazir Bhutto in December led to violent strikes and shutdowns. The food situation, therefore, was one of many crises that the government of the time faced as it saw its authority challenged. Administrative and regulatory measures exacerbated rather than alleviated shortages, and the government ultimately intervened directly by dumping large quantities of highly subsidised imported wheat flour to restore the market. Perceptions that the government had mishandled the management of food markets, and particularly the market for the key staple, further eroded the legitimacy of the military regime.
A new government took office in March 2008 following general elections, and promptly appointed a National Task Force on Food Security to investigate the causes of the food crisis and to offer recommendations. The Task Force found that the failure to raise the wheat procurement price in line with emerging global trends in 2007 had exacerbated price volatility in Pakistan, leading to hoarding, shortages and price spirals which were then broken with the use of expensive wheat imports. The Task Force recommended that the wheat procurement policy should aim to cushion the impact of global price volatility on local markets. It made explicit something which was already known and understood: growers responded to price signals, and it was impossible to insulate the national economy from global food prices, particularly due to active trade across the county's western borders. The wheat support price was raised and has been renewed on an annual basis with a view on world prices. The new government also introduced a cash transfer programme targeted to women in poor households (the Benazir Income Support Programme, or BISP). While it came to be seen as a flagship social protection scheme, the initial rationale for the programme was to provide food security at a time of rising food prices (Gazdar 2011).

The Musharraf government had correctly anticipated that announcing a higher wheat 
support price in October 2007 for the March-April 2008 harvest would lead to an immediate rise in market prices. Its popularity already in decline, the government was nervous about the political impact of a price change, and this, in part, was a cause of indecisiveness. ${ }^{5}$ But the food crisis showed that price spikes and market shortages can have bigger economic and political costs to government than a managed transfer of global price changes to consumers. The initial attempt to insulate consumers from the change in global price levels proved, ultimately, to be futile as domestic prices did finally rise. The fact that the government was seen as being unprepared for this eventuality led to hoarding and shortages, and domestic price movements ended up being even more volatile than global prices. Far from preventing a political fallout from global prices, the military regime lost further legitimacy as it was perceived as being weak and indifferent. The findings and recommendations of the National Task Force on Food Security were readily accepted because they were in line with the prior understanding within government circles - among politicians and bureaucrats alike - that the state's primary task with respect to food security is to ensure price stability and avert shortages. The Musharraf government was seen as having defaulted on this obligation.

\section{Concern about price volatility and market failure} was built into the everyday running of government well before the food crisis of 2007-08. The Economic Coordination Committee (ECG) of the Cabinet is a powerful organ of the federal government and meets every two weeks to coordinate fiscal, monetary and trade policies (Tahir 2005). One of its key tasks is to act as a watchdog on prices and shortages. The ECG regularly reviews the markets and price data supplied by over three dozen reporting stations of the Pakistan Bureau of Statistics spread across the country, and is empowered to intervene to prevent price spikes and shortages (Prikhodko and Zrilyi 2013; PBS 2012). Its focus is on 'essential commodities' such as wheat/wheat flour, cooking oil, sugar, tea, onions and potatoes - items that make up the basic food basket of the poor, but not necessarily nutritious foods. At lower tiers (provincial and municipal) the administrative machinery is also geared up for monitoring and regulating the prices and availability of 'essential commodities'. The title of the provincial law under which the monitoring agency operates - the 'Sindh Essential Commodities Price Control and Prevention of Profiteering and Hoarding Act of 2005' - makes clear how the mandate of government is understood.
Pakistan's political and administrative systems are attentive to price shocks of what are regarded as essential food commodities and there are mechanisms in place to monitor prices and to take prompt remedial action. The brief moment of breakdown in 2008 and the steps taken in its aftermath are instructive of the implied social contract which exists in the country around food security: it is predicated on preventing price spikes, spirals and shortages, in other words market breakdown, for 'essential commodities'.

\section{Insulation from prices: the food economy of the poorest}

\subsection{Hunger and food security}

In the course of our research, most of the households in both Gulshan-e-Iqbal Town in Karachi and Dadu District, Sindh Province areas reported some degree of vulnerability to hunger. Most households had faced hunger at least once in the preceding year, a condition which, according to the nationally representative National Nutrition Survey (NNS) 2011, corresponded with the experience of 10-30 per cent of the population.

Rural and urban informants in our fieldwork sites are similar in terms of the way in which food consumption priorities are discussed. Acquisition of the main staple (wheat flour) is the primary concern of most households. When urban and rural informants said they had 'nothing to eat', it was sometimes the case that they did not have a sufficient quantity of the main staple - roti (wheat flour flatbread). Further probing revealed, however, that having 'nothing to eat' often meant that there was roti but nothing to accompany it. Hunger is closely associated with frugality in terms of the lack of dietary diversity and micronutrient deficient intakes. Chutney made with salt and raw chillies, and sweetened black tea, are common accompaniments. Milk, if available, might be added to the tea. These accompaniments are used to make the simple roti more palatable. In the rural site there is also the use of lassi (buttermilk), which can be available free of cost from neighbours. ${ }^{6}$

In the rural site hunger occurs, for the most part, in the lean season, or when harvested grain runs out. Households' stocks of grain from their own farms, from harvest labour, or from alms and charity, see them through part of the year. Even though these households may have access to grain loans from landlords or shopkeepers, they are unable to fully stave off hunger while they make arrangements for alms or loans. There are also some households who 
rely on frequent purchases of flour, much like a poor urban household. These households can experience hunger regardless of the agricultural cycle, because they rely entirely on cash purchases from retail outlets for their staple food.

Households in the urban site are more dependent on the market for their food. There were some urban households with rural links who received grain from the village. For the most part, however, even recent rural-urban migrants in our urban site were entirely dependent on local purchasing. Urban households with government jobs, like their rural counterparts, plan their food acquisition over the monthly salary cycle. Others rely on more frequent purchasing from local retailers. Although urban households are somewhat better off than their rural counterparts in terms of work opportunities, the poorest here also experience hunger at least on some days. In fact, their risk of hunger is spread more evenly across the year with hungry days occurring due to the lack of cash on a day-to-day basis.

The shocks that affect the lives and food security of the poorest are mostly idiosyncratic in nature though some of these have linkages with broader economic and political trends. Illness, injury, the loss of a job, finding new employment, rural-urban migration, changing residence within the city, changes in family composition, family disputes and disruptions in social arrangements, are the types of events which lead to hungry days. In many cases these events or circumstances are correlated. The loss of a job, for example, can be associated with domestic violence and family breakdown. A dispute with a better-off relative can lead to the loss of livelihood and other forms of support, and even eviction from rent-free accommodation. Migration to the city for a job can be associated with the breakdown of a family, its later consolidation, and then its dispersal once again. A family member gaining public sector employment can lead to immediate improvements in creditworthiness and a rise in social stature among close relatives. All of these are actual examples from our respondents over the period that we visited them.

\subsection{Staving off hunger and coping on hungry days}

The household is ordinarily seen as a unit of consumption and welfare and the household budget as a measure of wellbeing. A closer view of the actual eating and food sharing arrangements in which individuals are involved reveals much fluidity across household boundaries. This is particularly true of households and individuals surviving on the margins of food insecurity and hunger. Mrs M., a 37-year-old urban factory worker urban informant, who sends her children to eat at her mother's house whenever there is not enough to eat is typical of the way in which the household breaks down as a unit of food consumption at moments of crisis. At the other end of the spectrum, in the same locality, a relatively well-off informant, the 36-year-old Mrs G., had invited a poor niece from the village to come and stay with her. The girl did household chores and was looked after in terms of food and other needs.

Apart from relatives, the main sources of informal local support in the face of adverse food shocks came from neighbours in the urban area, and the wider kinship group as well as landlords and patrons in the rural site. Some of the food sharing between urban and rural neighbours is not a response to an adverse shock, but simply an institutionalised form of circulation. It is also common for small quantities of cooked food to be sent to neighbours, particularly if something special has been prepared. There may be a religious element to such circulation, as food items that are made for special events are thought to bring blessings if shared with neighbours and relatives and there may be a seasonal element as well, since charitable giving increases during periods of religious significance. In any case, some of the sharing of cooked foods is part of the reciprocal exchange between people of similar status.

This form of reciprocal exchange often overlaps with charitable assistance. Since the motive of the giver might be religious blessings in both such cases, the boundaries between the two can be blurred. The difference is that in the case of charitable assistance, the giver and the receiver are both aware that reciprocity is not required. If the recipient is undergoing transitory distress there may be an implied understanding that in time she or he will be counted among peers again.

Beyond a point, however, the hierarchy of status between the giver and the receiver is clearly understood in terms of dependence and social obligation. While the circulation of food (particularly wheat loans, or even charity) in the rural area makes up for relative food security, it is also seen as a social cost. Mrs K., ${ }^{7}$ a 47-year-old rural-urban migrant in the Karachi fieldwork site, reflected on the availability of the staple in the village compared with greater insecurity in the city: 'This (urban) hunger is a blessing compared with being fed but also humiliated in the village by the patron'. 
Just as there is overlap between food circulation between peers and charitable giving, so there appears to be a grey area between charitable giving and begging. At the far end are professional beggars who are candid that living off alms is their traditional occupation. We had at least one such case in each of the two sites. Then there are those who are very poor or have fallen on hard times, and regularly depend on alms for their food consumption. Children play a key role, as in the case of fluid household boundaries, in the circulation of food even with respect to charity and alms. It is socially more acceptable for children to go over to houses of neighbours and ask for any spare food than it is for adults.

The food economy of the poorest on normal as well as hungry days can be somewhat insulated from food markets and prices. This is only because at extreme levels of poverty where food security is seen almost exclusively in terms of adequate quantities of bread or wheat flour, even basic accompaniments such as vegetables and lentils, which might be acquired from the market are seen as luxuries. For households which rely on the market the main source of vulnerability to their purchasing power, besides the price, is the income earned on the day. Many of the poorest are already part of a moral economy in which their need for the basic staple will mostly be met through some combination of sharing, charity and begging. Price changes are transmitted relatively quickly from global to local markets, but the food economy of the poorest is not always denominated in money terms. This is not to say, of course, that price increases or price volatility do not affect the food security of the poorest. But for those whose primary economic goal is to simply acquire a minimum quantity of staple food, the impact of prices and markets is transmitted through other mediating institutions and informal support systems.

While the food economy of the poor, which includes not only livelihood strategies but also social networks, provides protection from chronic hunger, it has three sets of salient implications. First, the presence of informal support systems might protect individuals from outright starvation, but not from temporary vulnerability to hunger. Second, the food economy of the poor holds individuals and households in an implicit social contract, which involves dependence, subservience and loss of status and agency. Mostly avoiding hunger, while remaining vulnerable to it, restricts options in all spheres of life, including family relations. Third, the overriding focus on avoiding hunger means that there remains a significant segment of the population for which concerns such as dietary diversity and the consumption of nutritious foods assume a lower priority.

The payment modality of the main social protection programme of the federal government (BISP) is based on the transfer of quarterly instalments. Hunger and food insecurity as experienced by the poorest, however, are at moments of crisis triggered by seasonality, individual or household contingencies such as ill-health or injury, loss of job, and disruptions in intra-household and wider social relations. While the food economy of the poor generally ensures the avoidance of hunger, it does not fully insure them against a hungry day. The fact that the cash transfer programme payments arrive at intervals of three months means that the programme staves off idiosyncratic hungry days only indirectly though the somewhat improved creditworthiness of beneficiaries with local retailers. Respondents report eating better on days when they receive their BISP payment, but the programme is unable, in its current form, to insure against hungry days if they happen to occur at other times.

The food economy of the poorest, therefore, operates beneath both the market and the state, for the most part. Prices have only a partial effect on the food security of the poorest who rely on a range of channels, many of them non-monetary ones, for their access to basic foods. Formal social protection, although successful in its outreach to the poorest, is also not a reliable foil against hungry days.

\section{Rights, entitlements and the politics of hunger}

FPV research provided insights into how the poor understand their rights and entitlements with respect to food. There was consensus among respondents that everyone had a right to food regardless of age, gender and social status. This 'right', however, was understood in consequentialist terms. Men had a right to food because they went out to earn and provided for their families; women had a right to food as they took care of the household and of children and if they did not get sufficient food an impact would be felt on others; and children had a right to food because they were young/innocent and could not fend for themselves. The right to food was not understood by our respondents as a specific legal or political entitlement individuals enjoyed as citizens of a state.

When asked who was responsible for ensuring that individuals did not go hungry, respondents 
identified a range of possible providers including God, household, community and the government. For some, God was responsible for ensuring there was enough food for individuals. Others felt that while God was responsible, individuals could not completely rely on His mercy and needed to make an effort to ensure they, and those for whom they were actually responsible, were fed. At the household level, there was a gendered division of roles whereby the husband or other male members had the responsibility to provide for women and children and in return women carried out care duties and looked after their husband and children. As the 60-year-old Mrs Z., ${ }^{8}$ who subsists on begging in the rural site put it: 'Whether one begs or earns, it is the responsibility of the head of the household to feed his family'.

When our respondents did actually mention a specific role for government with respect to food security, it was in terms of prices and shortages more or less the terms of the implied social contract which appears to guide government action. While in our research sites there was no explicit mention or awareness of the price control system, respondents did feel that food price inflation takes place because retailers and traders charge high rates to make large profits at the expense of the consumers. There was also a feeling that the government's responsibility should be limited to creating an environment where jobs are available and there is employment for all, so that individuals are able to provide for themselves. However, a sense of helplessness was prevalent among respondents as they felt that because of their poverty they lacked power to be able to voice their opinions. According to one of our household interview respondents in Karachi, they explained that it is better to stay quiet and at home and work hard to earn income rather than try to hold someone accountable for hunger.

\section{Notes}

1 See www.finance.gov.pk.

2 See www.pbs.gov.pk, the Pakistan Bureau of Statistics, formerly the Federal Bureau of Statistics.

3 See www.pbs.gov.pk/cpi.

4 See www.finance.gov.pk.

5 There was a similar reluctance to pass on fuel price increases, resulting also in heavy losses to the exchequer.
These observations from our FPV 'listening posts' are supported by a broader view of political mobilisation and articulation in Pakistan. Hunger or vulnerability to hunger did not become political issues in an otherwise competitive, even aggressively fought, election campaign in 2013. It is not as though consumer-related concerns were absent from the political debate. The government was held to account over shortages of electricity and subsidised fuel.

\section{Conclusion}

There is no contradiction between the absence of a political constituency for the eradication of hunger and undernutrition on the one hand, and the existence, on the other hand, of an implicit social contract on food security which appears to hold and deliver. Popular perceptions of food security as the ability to fill the belly of children, regardless of the nutritional adequacy and quality of the diet, are largely in agreement with policymakers' focus on 'essential' foods such as wheat. Government systems, representative as well as administrative ones, are also in concurrence with the societal view that the main job of the state is to ensure the predictability of prices, prevent shortages and act against blatant profiteering.

The informal social support systems which sustain the poorest are premised on a different implicit social contract - one that combines reciprocity, patronage and charity, all of which include a transactional dimension. It might be argued that the coexistence of these two types of social contract one based on market functioning, the other on the circulation of food within as well as outside market mechanisms - allows the mainstream representative and administrative systems to carry on functioning relatively smoothly while ignoring vulnerability to hunger and undernutrition.

6 The free circulation of lassi among neighbours appears to be a remnant of a wider moral economy in rural communities around surplus fresh milk and other perishable dairy products. The increasing commodification of fresh milk has led to a decline in its circulation.

7 Interview, 22 October 2012, Karachi.

8 Interview, 25 September 2013, Dadu District. 


\section{References}

Aga Khan University (2011) Pakistan National Nutrition Survey 2011, Islamabad: Government of Pakistan, Aga Khan University and UNICEF

Balagamwala, M. and Gazdar, H. (2014) Life in a Time of Food Price Volatility: Evidence from Two Communities in Pakistan, Working Paper 449, Brighton: IDS

Gazdar, H. (2011) 'Social Protection in Pakistan: In the Midst of a Paradigm Shift?', Economic and Political Weekly 46.28: 59-66

Gazdar, H. and Mallah, H.B. (2010) 'Inflation and Food Security in Pakistan: Impact, Policies and Coping Strategies', mimeo, Collective for Social Science Research, Karachi
Iqbal, S. (2007) 'State Bank Moves to Cage Wheat Prices', Dawn, 13 December, www.dawn.com/ news/279985/state-bank-moves-to-cage-wheatprices (31 July 2015)

PBS (Pakistan Bureau of Statistics) (2012) Methodology of Price Collection and Computing Price Indices, PBS, www.pbs.gov.pk/sites/default/files/ price_statistics/methodology_price.pdf (accessed 13 August 2015)

Prikhodko, D. and Zrilyi, O. (2013) Pakistan: Review of the Wheat Sector and Grain Storage Issues Country Highlights, Rome: Food and Agriculture Organization Tahir, P. (2005) 'Institutional Machinery for Managing the Pakistan Economy', Lahore fournal of Economics 10 (Special Edition): 106-43 